Swarthmore College

Works

$5-1-2014$

\title{
Introductory Physics In Biological Context: An Approach To Improve Introductory Physics For Life Science Students
}

\author{
Catherine Hirshfeld Crouch \\ Swarthmore College, ccrouch1@swarthmore.edu \\ K. Heller
}

Follow this and additional works at: https://works.swarthmore.edu/fac-physics

Part of the Physics Commons

Let us know how access to these works benefits you

\section{Recommended Citation}

Catherine Hirshfeld Crouch and K. Heller. (2014). "Introductory Physics In Biological Context: An Approach To Improve Introductory Physics For Life Science Students". American Journal Of Physics. Volume 82, Issue 5. 378-386. DOI: 10.1119/1.4870079

https://works.swarthmore.edu/fac-physics/81

This work is brought to you for free by Swarthmore College Libraries' Works. It has been accepted for inclusion in Physics \& Astronomy Faculty Works by an authorized administrator of Works. For more information, please contact myworks@swarthmore.edu. 


\section{AMERICAN \\ JOURNAL \\ of PHYSICS}

\section{Introductory physics in biological context: An approach to improve introductory physics for life science students}

Catherine H. Crouch and Kenneth Heller

Citation: American Journal of Physics 82, 378 (2014); doi: 10.1119/1.4870079

View online: http://dx.doi.org/10.1119/1.4870079

View Table of Contents: http://scitation.aip.org/content/aapt/journal/ajp/82/5?ver=pdfcov

Published by the American Association of Physics Teachers

\section{Articles you may be interested in}

Entropy and spontaneity in an introductory physics course for life science students

Am. J. Phys. 82, 394 (2014); 10.1119/1.4870389

Rounding off the cow: Challenges and successes in an interdisciplinary physics course for life science students Am. J. Phys. 80, 913 (2012); 10.1119/1.4733357

The Challenge of Teaching Introductory Physics to Premedical Students

Phys. Teach. 45, 552 (2007); 10.1119/1.2809149

Adaptation and Implementation of a Radically Reformed Introductory Physics Course for Biological Science Majors: Assessing Success and Prospects for Future Implementation

AIP Conf. Proc. 883, 113 (2007); 10.1063/1.2508705

Modules to teach physics to biology and premedical students and biophysics to physics students AIP Conf. Proc. 399, 869 (1997); 10.1063/1.53194

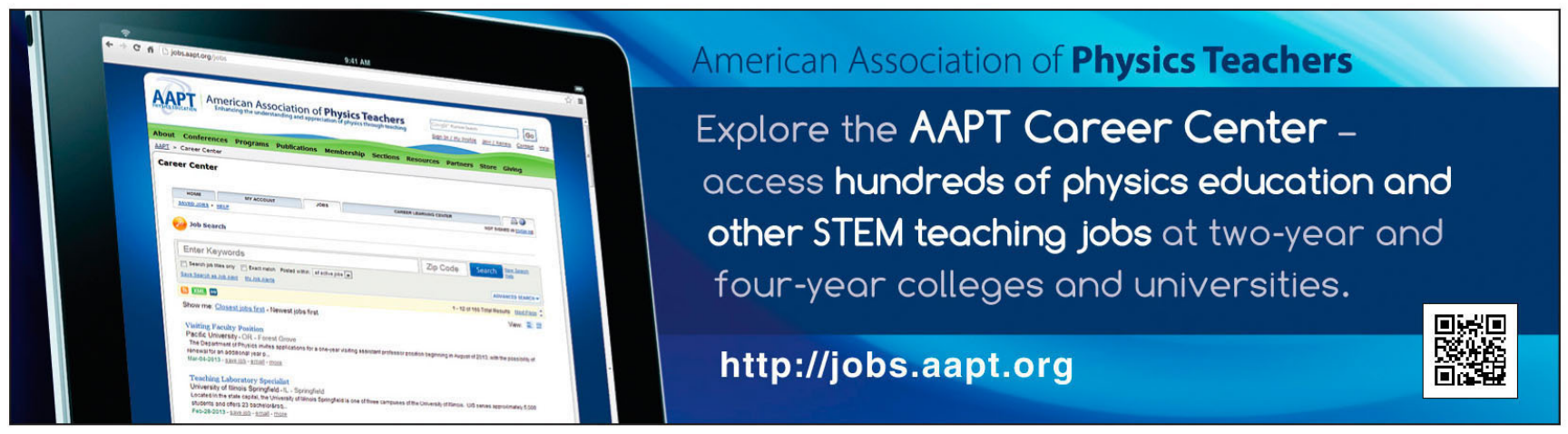




\title{
Introductory physics in biological context: An approach to improve introductory physics for life science students
}

\author{
Catherine H. Crouch ${ }^{\text {a) }}$ \\ Department of Physics \& Astronomy, Swarthmore College, Swarthmore, Pennsylvania 19081 \\ Kenneth Heller ${ }^{\mathrm{b}}$ ) \\ School of Physics \& Astronomy, University of Minnesota, Minneapolis, Minnesota 55455
}

(Received 20 August 2013; accepted 20 March 2014)

\begin{abstract}
We describe restructuring the introductory physics for life science students (IPLS) course to better support these students in using physics to understand their chosen fields. Our courses teach physics using biologically rich contexts. Specifically, we use examples in which fundamental physics contributes significantly to understanding a biological system to make explicit the value of physics to the life sciences. This requires selecting the course content to reflect the topics most relevant to biology while maintaining the fundamental disciplinary structure of physics. In addition to stressing the importance of the fundamental principles of physics, an important goal is developing students' quantitative and problem solving skills. Our guiding pedagogical framework is the cognitive apprenticeship model, in which learning occurs most effectively when students can articulate why what they are learning matters to them. In this article, we describe our courses, summarize initial assessment data, and identify needs for future research. () 2014 American Association of Physics Teachers.

[http://dx.doi.org/10.1119/1.4870079]
\end{abstract}

\section{INTRODUCTION: WHY TEACH PHYSICS IN BIOLOGICAL CONTEXT?}

As the understanding of the physical mechanisms of biology increases, and as physics-based technological tools permeate both biological research and clinical medicine, national reports from the life science (e.g., BIO 2010 ${ }^{1}$ and Vision \& Change ${ }^{2}$ ) and medical (e.g., Scientific Foundations for Future Physicians ${ }^{3}$ ) communities stress the value of a deeper understanding of fundamental physics principles, particularly those most relevant to the life and medical sciences, as well as a high level of problem solving and mathematical skills.

However, typical physics courses for life science students are not well designed to meet these goals. In such courses, important fundamental concepts such as energy and entropy are often taught with a restricted focus on conditions irrelevant to biology, such as considering only closed rather than open systems. Essential physics topics for biologists, such as fluid statics and dynamics, diffusion and osmosis, and the effect of dielectrics on electrical interactions, are given little time or omitted altogether. ${ }^{4}$ If biologically related examples are included, they rarely involve contexts in which physics gives genuine insight into biology or medicine ("authentic" problems"6) and may even describe physically inappropriate situations.

To address these needs, there is currently a widespread effort to reform the introductory physics course for life science students, both within the physics education research community and among physics educators more broadly. ${ }^{7-9}$ These courses are being designed to emphasize the topics that are most important for these students and to help students develop the skills needed to apply physics to life science problems.

In this article, we describe two related (though independent) reformed courses. The organizing principle is that physics is taught in biologically appropriate contexts, both to make clear the value of physics for the life sciences and to give students practice applying fundamental physics to biological situations. ${ }^{10-13}$ To accomplish these goals, each of us has modified the course syllabus to be more closely aligned with the material most important for the life sciences and medicine, while maintaining the fundamental concepts, skills, and values of physics. To develop conceptual understanding and problem solving skills, our courses use previously validated pedagogies from the physics education research community. The guiding pedagogical framework for choosing both the content and the pedagogy is the cognitive apprenticeship model of student learning, which stresses the importance of a context meaningful to the student for learning. ${ }^{14}$ Indeed, there is some evidence that explicitly presenting a learning activity as supporting the student's longerterm learning goals aids in such transfer of knowledge from one domain to another. ${ }^{15,16}$

In order to add to the knowledge base about designing such courses, we give an overview of the redesign process each of us followed, guided by the same principles but implemented at two very different institutions: the University of Minnesota and Swarthmore College. Although we benefited from extensive discussions and by sharing materials with each other and with other IPLS reformers, our courses developed independently and thus have features specific to our individual settings and constraints.

We also describe initial outcomes in both student attitudes and conceptual learning, as measured by standard introductory physics assessment tools. Finally, we identify a set of research directions to inform future development and implementation, focused particularly on addressing challenges to the development and widespread adoption of such courses. Our experiences, and those of other developers, indicate that designers of such IPLS courses face many challenges. Despite including published or freely available text material, ${ }^{17}$ many of these courses have not become widespread. For this reason, we have gone through several iterations of the scope and sequence of this course to make it both accessible to our students and acceptable to our fellow physics faculty. We hope this article will help encourage increasingly broad efforts in curriculum development and adaptation, and the research needed to support them. 


\section{PHYSICS IN BIOLOGICAL CONTEXT AT MINNESOTA AND SWARTHMORE}

The University of Minnesota and Swarthmore College span a large, though by no means the entire, range of teaching environments, faculty, and students. Minnesota is a large state university with an emphasis on research as well as undergraduate and graduate education. Swarthmore is a highly selective private undergraduate college with a strong faculty commitment to undergraduate education. Both traditionally offer a calculus-based course in introductory physics for life science students, and both have recognized that this course needs a redesign to focus on the most important topics and skills for its student population.

At Minnesota, the IPLS course is a yearlong course for biological science majors and pre-medical students that has 3 concurrent lecture sections taught by different professors with between 120 and 200 students in each. Students also participate in coordinated weekly discussion and laboratory sections of 18 students. Pedagogically, the course is built around Cooperative Group Problem Solving.

At Swarthmore, the total enrollment in introductory physics is $90-120$ in the first semester and somewhat less in the second semester. All students (including prospective engineering majors, chemistry majors, and pre-medical students) take a standard first semester of introductory physics. Since Spring 2008, a modified (IPLS) second semester has been offered in addition to the standard second semester; most chemistry majors take the IPLS course. Up until now, the resources have not been available to also offer an IPLS first semester, but due to the success of the second semester, development has begun for a modified first semester to be offered in Fall 2015. The IPLS class meetings include $3 \mathrm{~h}$ of a 40-60 member class taught with Peer Instruction and a weekly $3 \mathrm{~h}$ laboratory in sections of 15 .

\section{A. Course goals and development}

Our modified courses have two primary goals for the students. Specifically, these goals are (1) to appreciate the power of the very few fundamental principles of physics, particularly their applicability to biological as well as physical systems, and (2) to gain the ability to make and solve physics models of complex systems, particularly biological systems, as recommended by both the HHMI-AAMC report ${ }^{3}$ and the AAAS Vision \& Change report. ${ }^{2,18}$

To accomplish these goals, lectures, group activities in the discussion and laboratories, and homework problems demonstrate and give students practice with the process of making simplified physical models. This process begins with a conceptual description of the essential elements of the system, followed by expressing the model mathematically. Throughout, instruction and student activities emphasize the importance of approximations and estimations, and testing the reasonableness of conclusions. In the laboratory, students similarly use an appropriate model for the situation they are investigating, test their model by making measurements, and analyze and evaluate the accuracy of their measurements.

In support of these pedagogical goals, the physics topics and scientific skills explicitly taught in the course were selected in consultation with life science and medical professionals to be relevant to beginning students in the life sciences. In addition, we tried to maintain a balance between the needs of the life science students with the constraints of effective pedagogy for introductory physics students and the construction of a coherent view of physics as a discipline. In this remodeling, we sought to keep the changes to the traditional course as modest as possible, while still making the course effective for these students, so that the course was more likely to be adopted by other faculty.

To design this curriculum, the developer (CHC at Swarthmore, KH at Minnesota) first prepared an initial syllabus and list of candidate biological contexts based on the BIO 2010 report, previous interactions with colleagues in the biological sciences, materials from the literature ${ }^{19}$ and existing courses, ${ }^{17}$ and their individual knowledge of applications of physics in the life sciences and medicine. In addition, at Minnesota, a sample of life science faculty from diverse departments was surveyed for their input on the most important goals and topics of an introductory physics course. The five highest-rated goals were:

1. know the basic principles behind all physics;

2. solve problems using qualitative problem solving skills;

3. solve problems using quantitative problem solving skills;

4. provide biological examples about physics principles; and 5. overcome misconceptions about the physical world.

Of the 18 candidate goals listed, those concerning the laboratory were rated significantly lower than the others and preparing students for the MCAT was the lowest. ${ }^{20}$

In the second step, the proposed syllabus was discussed with faculty in physics, biology, and biochemistry to refine it and arrive at a course that was acceptable to all stakeholders. Meetings with biology and biochemistry colleagues were particularly important in determining the relative importance of physics topics for life science students and their difficulty for students when applied within biology or biochemistry classes. The life science faculty also provided examples of how these topics were applied in their courses and, at Swarthmore, in research experiences that students might have with faculty. At Swarthmore, a daylong workshop was held for biology, biochemistry, and physics faculty to discuss the course, bringing in presenters from a leading local medical school and three reformed introductory physics courses at other institutions.

Once the course topics were selected, both developers used their expertise in research-validated physics pedagogies and curricular materials to adapt existing pedagogies and materials. Such a significant revision to the introductory course is not accomplished all at once. With each offering of the IPLS courses, the materials are revised both to better support student learning and to be acceptable to physics faculty who participate in teaching the course but are not themselves its developers and often have little or no background in the biological sciences.

\section{B. Syllabus}

Our course design process identified certain topics that are commonly omitted or minimally taught, as very important for life science and premedical students, including:

- fluid statics and dynamics, and motion of objects in fluids

- diffusion

- osmotic pressure

- geometric and physical optics

- the effect of dielectrics and conducting solutions on electrostatics

- radiation and its interaction with matter 
To provide the time needed to add some of these topics with sufficient attention that students achieve an adequate level of understanding, difficult choices need to be made. For example, the first semester at Minnesota significantly reduces the time spent on kinematics, omits momentum and angular dynamics (angular momentum, angular acceleration, moment of inertia), and introduces torques only in the context of static equilibrium. Although these omitted topics are important and can be powerful and useful in biology, a faculty committee judged that their importance for biology majors did not justify the time and effort needed for students to understand them. Indeed, these topics will be omitted from the 2015 version of the MCAT. ${ }^{21}$

In the second semester, both of our courses omit Gauss's Law, and at Swarthmore we also omit Ampere's Law and minimize calculation of magnetic fields. At Swarthmore, we approach the calculation of electric and magnetic fields in two ways: (1) through touchstone examples of configurations of charge or current, in which the resulting fields are calculated once (or motivated qualitatively as in a couple of cases) and then used thereafter; (2) in the case of electric fields, through simulations that allow students to visualize combining many point charges into a charge distribution and the resulting field. This allows us to significantly reduce the time spent on techniques for calculating fields. At Minnesota, we model complex charge or current distributions by simple ones and always calculate the field from first principles.

Also in the second semester, at both institutions, we omit ac circuits and formal treatment of inductors and inductance, and consider inductive phenomena purely through Faraday's Law. Finally, we omit quantitative discussion of Maxwell's equations and provide a purely qualitative motivation for the existence of electromagnetic waves without demonstrating the existence of solutions to the differential equations. These changes are summarized in Table I and are provided to illustrate possible ways to make the difficult choices that are necessary; other reasonable choices are certainly possible. There are differences between Minnesota and Swarthmore, illustrating that these choices are always subject to institution and instructor priorities, constraints, and opportunities. The supplementary information provides syllabi for each institution. ${ }^{20}$

Equally important to these additions and omissions is a change in the approach to energy and entropy, necessary because the standard introductory physics approach is very foreign to biology. In biology, there are no closed systems; energy transfers and conversion between different forms of energy are critically important. Moreover, thermal energy (explained as kinetic energy of random motion of atoms or molecules), electrical and chemical forms of potential energy (including energy carried by light), as well as entropy-driven "free energy," are ubiquitous in biology, while work and heat show up in relatively few, specialized contexts. Consequently, at Minnesota, although the study of energy begins with mechanical energy, as this allows students to connect the concept of energy to concrete experience, the principle of conservation of energy is developed without restriction to mechanical systems. Both energy transfer in and out of a system, and transformation of one form of energy to another within a system, are emphasized because of their centrality to biology. Swarthmore's first semester course (to be launched in Fall 2015) will incorporate these approaches. At both institutions, energy conservation carries forward as an important theme in the second semester.
Table I. Changes to the syllabus at Minnesota (both semesters) and Swarthmore (semester 2 only as explained in Sec. II). Topics not listed, such as forces (first semester) and wave optics (second semester) are covered at approximately the same depth and level as in the typical syllabus. At Swarthmore calculation of magnetic fields is also largely omitted.

\begin{tabular}{|c|c|c|}
\hline Semester & Topic & $\begin{array}{l}\text { Nature } \\
\text { of change }\end{array}$ \\
\hline \multirow[t]{10}{*}{1} & Kinematics & Reduce \\
\hline & Momentum & Omit \\
\hline & Torque (consider statics only) & Reduce \\
\hline & Angular velocity, momentum, dynamics & Omit \\
\hline & Fluids (statics and dynamics) & Add \\
\hline & Drag force and motion through fluids & Add \\
\hline & Diffusion and osmotic pressure & Add \\
\hline & Thermodynamic cycles & Increase \\
\hline & Statistical treatment of entropy & Add \\
\hline & Free energy & Add \\
\hline \multirow[t]{8}{*}{2} & Geometric optics & Increase \\
\hline & Gauss's Law & Omit \\
\hline & Electrostatics in media and in salt water & Increase \\
\hline & RC circuits & Increase \\
\hline & Induction (Lenz's Law and Faraday's Law only) & Reduce \\
\hline & $\begin{array}{l}\text { Inductance and inductors in circuits, } \\
\text { AC circuits (with alternating sources) }\end{array}$ & Omit \\
\hline & $\begin{array}{l}\text { Maxwell's equations, calculation of } \\
\text { induced electric or magnetic fields }\end{array}$ & Omit \\
\hline & Radiation-matter interactions & Add/Increase \\
\hline
\end{tabular}

\section{Pedagogical framework: Cognitive apprenticeship}

Cognitive apprenticeship provides the pedagogical framework for our courses. This theory combines the recognition that learning complex cognitive skills (e.g., reading or problem solving) requires more than the mastery of their subskills with the insight that apprenticeship is the most successful form of education across history in all human cultures. Although standard classroom practice has pushed apprenticeship out of mass education, it is still used in areas where a high level of mastery is sought, such as academic research, medicine, the performing arts, sports, and the trades.

The developers of cognitive apprenticeship give a pedagogical framework for classroom-based education by analyzing the essential elements of apprenticeship in light of modern learning theory. ${ }^{22}$ In the process, they clarify the basis for the success of many research-validated teaching techniques. Here, we summarize this framework briefly, emphasizing those aspects most relevant to our courses.

Cognitive apprenticeship involves establishing an environment of expert practice, and iterating among the instructional approaches of modeling, coaching, and fading, all supported by scaffolding. In traditional apprenticeship, the environment of expert practice means that skills are learned in the same environment in which an expert uses them; for example, a graduate student learns to do scientific research by participating in a research project in a research laboratory. Such an environment constantly prompts the learner to answer three questions:

(1) Why is what I am learning important?

(2) How is what I am learning connected to other things I know? And,

(3) How can I use what I am learning? 
In cognitive apprenticeship, the teacher seeks to create a classroom environment that, as far as possible, also enables students to answer these questions. To teach physics to students motivated by the life sciences, we surmise that the environment of expert practice can be most naturally achieved by integrating biological contexts into the heart of the course.

In our courses, modeling, coaching, scaffolding, and fading are provided as follows. The instructor first demonstrates conceptual reasoning and the process of solving complex problems as part of the interactive lectures. The instructor explicitly verbalizes the usually internal decision-making process involved; this is the modeling stage. Coaching is provided by peers during discussion of direct conceptual questions and the initiation of problem solutions in lecture and by peers and instructors in structured group problem solving or laboratory sessions. Activities and problems are also designed to include scaffolding that helps students succeed when they are still learning a skill, both content-specific scaffolding and a general problem-solving framework. Finally, fading is accomplished by gradually reducing scaffolding as students progress through a unit and through the course. The more proficient a student becomes, the more they are able to observe from modeling and the more they are able to gain from coaching.

\section{Instructional strategy of our IPLS courses}

To create the environment of expert practice, each topic is motivated by and organized around a small number of important biological examples, provided in the Supplementary Information. Capstone examples for each unit include: biomechanics, blood flow, and temperature regulation in the first semester; vision, nerve signaling, pacemaker safety, and confocal microscopy in the second semester. Conversations with our life science colleagues were essential in identifying good examples.

By their very nature, biological examples are more complex than examples commonly used to teach introductory physics, so it is critically important to balance the need for biological context with the use of simpler physical examples that more directly illustrate the physics topics. These two priorities are explicitly connected in the course by emphasizing the process of making simplified physical models of complex systems. ${ }^{23}$

Our typical instructional sequence (illustrated schematically in Fig. 1) is as follows:

- Each physics principle is introduced using a biological example to motivate and set the context. The example is often framed as a puzzle to be understood or a problem to be solved.

- Students prepare for class by reading a section from the textbook that introduces the material, and answering (via an online questionnaire) one or two questions designed to help them think about the ideas from the reading. ${ }^{24}$ They are also prompted to ask questions about the reading. Student responses are often used to start the class.

- Qualitative reasoning skills are developed with the new principle by applying it to some simpler physical contexts, preferably contexts with a connection to students' ordinary experience. ${ }^{25}$ Students practice these skills by participating in research-based activities such as ConcepTests, ${ }^{26}$ including Ranking Tasks, ${ }^{27}$ both in the physical contexts and biological contexts. Successful activities that were originally developed with physics contexts are adapted to biological contexts when it is natural to do so.

- Interleaved with qualitative reasoning, problem-solving skills are developed and new physics principles are

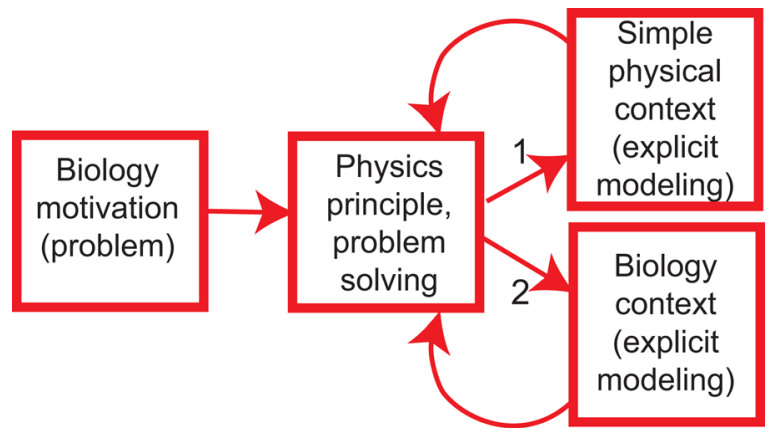

Fig. 1. Schematic illustrating the instructional cycle: A topic is introduced with a biological motivation, explored using physics contexts that have been shown to be effective for instruction, and finally the topic is applied to a biological problem (usually the original biological motivation).

explicitly linked with previous principles by solving context-rich problems ${ }^{28,29}$ throughout the course. These problems involve a biological context when appropriate.

- Problem-solving laboratories ${ }^{30}$ are also used to help students learn to develop physical models for biological processes. In these laboratories, scientific questions are posed in the form of context-rich problems. These questions prompt students to devise an appropriate physical model for a biological situation they might wish to investigate, test their model using measurements they decide upon, analyze their results in a manner that confirms or refutes their model, and evaluate the accuracy of their measurements.

\section{E. Case study: Geometric optics}

Geometric optics provides a good case study of our approach. Its relevance for both animal vision and research instrumentation makes it an engaging topic for life science students. Furthermore, this subject is a good example of how a simple conceptual model, that light travels in straight lines, combined with appropriate mathematics (mostly trigonometry), predicts complex and useful results. When this topic is included in a standard physics course, it is often reduced to the formulaic study of lenses and mirrors with a few equations and a lot of rules.

In our modified physics courses, the instructor begins ${ }^{31}$ by presenting the goal of studying geometric optics: to understand the diversity of animal vision, including the advantages and shortcomings of different types of eyes, and the workings of microscopes and other optical instruments used to augment and correct vision. ${ }^{32}$ As informed by the cognitive apprenticeship ${ }^{14}$ and expansive framing ${ }^{15,16}$ basis for our pedagogy, students are explicitly invited to use knowledge and raise questions from their personal experience and other courses. For example, the instructor frequently prompts students to consider their own experiences with corrective lenses, microscopes used in biology courses or research, and other optical instruments they have seen or read about. The instructor also emphasizes the value of learning this material to future work in their chosen fields.

The first problem posed is the simplest way to form images, the basis of vision in some invertebrates as well as pinhole cameras. This image formation process is developed from the ray model of light: namely, light travels in straight lines and can be redirected upon interaction with objects by reflection and refraction, or can be absorbed. After the instructor gives a brief summary of the core ideas, students discuss a series of conceptual questions ${ }^{33}$ in small groups. 
(1) A converging lens is used in a projector to form an image of a bright light source on a screen.

- If the screen is moved toward the lens, to keep the image in focus, how should you move the source?

- Is the new image bigger or smaller than the old? Is there anything else noteworthy about the image?

(2) When focused on a nearby object, your eye's lens and cornea combine to give a single focal length. To focus on a distant object, how must that focal length change?

(3) When focused on a nearby object, your eye's lens and cornea combine to give a single focal length. To focus on a distant object, how must the shape of your eye's lens change?

(4) You are working in a group investigating the evolution of the eye. Assuming that early animals had eyes that did not have an adjustable lens, you have been asked to determine the distance from the cornea to the retina of this type of eyeball as a function of the radius of the cornea and the index of refraction of a single fluid between the cornea and the retina. To survive these animals needed to be able to focus very distant objects on their retina. You assume that the cornea is a thin transparent layer with the same index of refraction as the fluid.

Since you are dealing with very distant objects, all of the angles involved are very small.
- Requires students to translate a verbal description into a problem

- Connects to real-world situations

- Students encouraged to use multiple representations: both geometry (ray diagrams) and algebra

- Algebraic approach uses qualitative reasoning with equations

- Same thinking skills as (1)

- Biological context

- Same thinking skills as (1)

- Biological context

- Students must reason using principle of refraction and geometry

- In discussion, instructor connects change of shape to relaxing eye muscles

- Requires student to translate a verbal description in terms of physiological structures into a mathematical model using the ideas of lenses, objects, and images

- A novel situation (no previous discussion by the instructor or the text of an eye with only a cornea)

- Biological context analyzed using simplified model
Subsequently, context-rich problems using these ideas are solved, some modeled by the instructor and others solved by students in cooperative groups.

Teaching image formation with lenses and lens combinations begins with students discussing a series of established PER-based conceptual questions and problems. ${ }^{34}$ However, there are important differences between how a physics course typically approaches lenses and lenses in biological contexts. For example, in most physics courses, image formation involves lenses with fixed focal lengths and variable image distances; the human eye includes an adjustable focal length lens at a fixed distance from the retina. In our courses, students proceed from fixed focal length lenses to more biologically appropriate scenarios using conceptual questions and context-rich problems. They finish with problems involving multiple lenses, and a problem-solving laboratory in which they devise and test models of vision correction and microscope focusing.

Table II provides a sampling of such questions and a problem to illustrate the kind of thinking our students are asked to engage in. The detailed syllabus and complete list of biological contexts used in our courses, along with the in-class activities, homework problems, and laboratories discussed in this article, are provided online. ${ }^{21}$

\section{ASSESSMENT AND DISCUSSION}

As part of evaluating our initial modifications of this course, we have used standard introductory physics assessment tools to examine student attitudes toward learning physics and their understanding of some of the fundamental physics concepts. At Swarthmore, other survey questions, including some constructed by an evaluator from the biology department, were also used for an initial evaluation of students' responses to the biological contexts. Recently, a more detailed study of these contexts was carried out by $\mathrm{CHC}$ and colleagues and is reported elsewhere. ${ }^{35}$

\section{A. Student attitudes}

Student attitudes toward learning physics were measured using the Colorado Learning About Science Survey $(\mathrm{CLASS})^{36}$ at the beginning and end of the semester, both in the redesigned courses and more traditional courses. As shown in Fig. 2(a), attitudes at Minnesota improved or remained stable for both semesters of physics in biological context, while attitudes became less favorable in the traditional course (taught with reformed pedagogy but standard physics content, lacking the biological contexts). In the second semester IPLS course, not only did attitudes overall improve but also improvement was seen in every category on the CLASS survey. Due to the challenges of developing the IPLS course, the IPLS semesters were not offered sequentially, so students in the second semester IPLS course had taken a traditional first semester course. Thus each IPLS course resulted in CLASS improvements independently.

At Swarthmore, CLASS data were obtained for the life science students in the standard first semester (also taught with Peer Instruction and the same textbook) and the IPLS second semester. The results show the same trend [Fig. 2(b)]; attitudes become less favorable in the traditional course and stay steady in the IPLS course. A more detailed analysis is presented elsewhere. ${ }^{37}$

While the improvements shown in Fig. 2 are small, they are noteworthy because introductory physics courses, including those taught with research-based curriculum that show high conceptual gains, typically show a decline in favorable CLASS responses, unless attention is specifically paid to cultivating expert-like attitudes and beliefs about learning physics. $^{36,38}$

In addition, after the third and fourth offerings of the IPLS course at Swarthmore, on the end-of-semester course evaluation, students were asked to complete the following pair of 

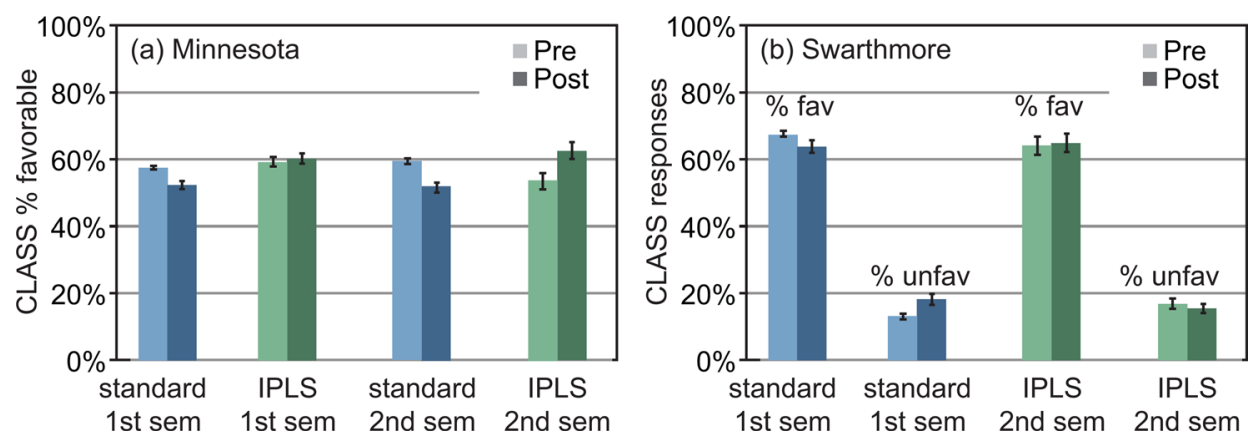

Fig. 2. Pre/post responses to the Colorado Learning About Science Survey (CLASS) from (a) University of Minnesota, standard content (pedagogically reformed, $\left.N_{1 \text { st sem }}=1503, N_{2 \text { nd sem }}=1182\right)$ and IPLS $\left(N_{1 \text { st sem }}=140, N_{2 \text { nd sem }}=95\right)$ courses; and (b) Swarthmore, first semester standard $(N=83)$ and second semester IPLS $(N=59)$ courses. From University of Minnesota, only \% favorable responses are shown; from Swarthmore both \% favorable and \% unfavorable are shown, as the $\%$ unfavorable changes are more significant (in the standard course, the decrease in $\%$ favorable is significant at the $p<0.05$ level, and the increase in \% unfavorable is significant at the $p<0.001$ level).

statements: ${ }^{39}$ "At the beginning of this course, I expected physics to be... in understanding the life sciences" and "Now, at the end of this course, I consider physics to be... in understanding the life sciences" with one of four choices provided. The results, shown in Fig. 3, show that students' opinion of the usefulness of physics for understanding the life sciences improved markedly, in contrast to Kortemeyer's findings. ${ }^{38}$

Finally, after the second offering of the IPLS course, an evaluator from the biology department ${ }^{40}$ surveyed the students on their interest in and appreciation of the role of the biological contexts in the modified physics course. As shown in Table III, he found significant student agreement with statements such as "Including biological examples helped me enjoy physics more than if we had used non-biological examples;" "Understanding aspects of physics that we learned in this course are useful for solving real-world problems in medicine, agriculture, the environment, and other topics in biology;" and "This course helped me think about biology in useful new ways." These indications that the use of biological examples was both generally motivating, and also helped students see the value of physics for their chosen fields, was supported by comments from course evaluations and unsolicited feedback from students. Recently, a more extensive study of the effectiveness of the life science examples in supporting student interest and learning was carried out at Swarthmore; these results are consistent with and expand upon the earlier evaluation and are reported fully elsewhere. ${ }^{36}$

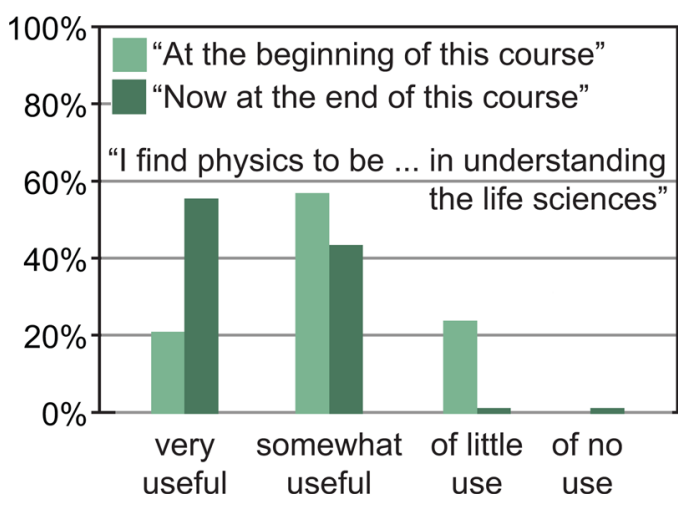

Fig. 3. Swarthmore end-of-semester survey responses $(N=68)$ to the pair of statements "At the beginning of this course, I found physics to be... in understanding the life sciences" and "Now at the end of this course, I find physics to be... in understanding the life sciences." Data shown are from Year 3, similar results in Year 4.

\section{B. Content learning}

Although existing conceptual inventories such as the Force Concept Inventory (FCI ${ }^{41}$ and the Brief Electricity and Magnetism Assessment (BEMA) ${ }^{42}$ are not well matched to the redesigned course content, they were nevertheless administered to give an indication of how well students learned the basic physics concepts. At Minnesota, data have been obtained for both the standard course and the redesigned curriculum. As shown in Fig. 4(a), for both the first semester, in which the FCI was given, and the second semester, in which the BEMA was given, students in the redesigned course scored substantially better on the post-tests, while pre-test scores were very similar for both the standard and redesigned courses.

At Swarthmore, BEMA data [Fig. 4(b)] were obtained for the IPLS course in each year it was offered. Data were also obtained from one offering of the traditional course in a year that the IPLS course was not offered (2011), but the post-test response rate of life science students was low ( $N=12$ out of 30 ), leading to weak statistics. Nevertheless, those 12 students were statistically indistinguishable in terms of course performance from the population of all life science students in that course, as measured by their average scores on all course exams. This suggests that most likely, the students in the IPLS course at least perform no worse on the BEMA than they would in the traditional class.

\section{Discussion}

The intent of these course reforms is that, if successful, students will find physics taught in biological context more clearly connected to their areas of interest. The cognitive apprenticeship pedagogical framework suggests that this clearer connection will both be more motivating and also will help students connect what they are learning to existing knowledge, facilitating learning and long-term transfer.

These initial assessment data suggest that even in our current implementations, teaching physics in a biological context leads to improved attitudes and beliefs about learning physics, and that students find the biological contexts engaging and motivating. As far as these data go, students also learn the fundamental physics concepts at least as well as in the standard course. An important area for future effort is the development of assessment instruments better matched to the course content. ${ }^{43}$ Other important directions for future research are a detailed examination of student skill development ${ }^{44}$ and tracking students' application of the ideas and skills taught through 
Table III. Additional attitude assessment data obtained from Swarthmore College (items designed by Philip Kudish). Students responded to each statement on a scale of 1 to $4,1=$ "strongly disagree," $4=$ "strongly agree." Responses are average \pm standard error $(N=52$, total enrollment $=61)$.

Average response, 1 = "strongly disagree," $4=$ "strongly agree"

Including biological examples helped me enjoy physics more than if we had used non-biological examples.

$3.6 \pm 0.1$

Including biological examples helped me understand physics more than if we had used

non-biological examples.

This course helped me think about biology in useful new ways.

$3.3 \pm 0.1$

$3.4 \pm 0.1$

$3.3 \pm 0.1$

Methods I learned in physics will be useful in my future career.

Understanding aspects of physics that we learned in this course are useful for solving real-world

problems in medicine, agriculture, the environment, and other topics in biology.

$3.4 \pm 0.1$

later biology courses. One step in this direction would be to develop an artifact-based interview protocol to probe student recognition of physics principles in a biology course.

\section{ADDITIONAL FUTURE RESEARCH DIRECTIONS}

1. We identify two further research questions ${ }^{45}$ that are particularly aimed at supporting development and widespread adoption of IPLS courses:

2. What are the characteristics of effective biological contexts?

3. What characteristics of IPLS courses are necessary so that physics faculty who are neither IPLS developers nor biological physicists will teach them?

Below we give more detail on each of these directions.

\section{A. Designing effective biological contexts}

A critical question for developers is: What characteristics make biological contexts effective for:

- learning fundamental physics principles and quantitative skills such as model building and problem solving,

- creating an environment of expert practice in which students can articulate why what they are learning will support goals that matter to them.

These questions can be addressed by surveying or interviewing students and examining appropriate written work, leading to standard instruments for assessing these topics. Interviews can also provide data on whether an environment of expert practice has been created in the student's mind. Based on such assessments, the contexts and content used can be refined or changed to make the course design suitable to a particular instructor and institution. For example, initial exploratory work in this area by Wisittanawat, Renninger, and Crouch ${ }^{36}$ found that certain contexts were more effective than others at engaging student interest, most likely due to being more familiar to students from prior coursework or experience.

Ultimately, a body of research is needed to produce guidelines for developers to design effective biological contexts, and for adopters to select most effectively from existing materials, as well as to modify them to best fit the local environment.

\section{B. Designing a readily adoptable course}

In their studies of other physics educational innovations, Henderson and Dancy have shown that developing a successful instructional approach with comprehensive supporting material and making those materials widely available are not sufficient for wide-scale adoption. ${ }^{46}$ Previous work by the University of Minnesota Physics Education Group and collaborators ${ }^{47,48}$ indicates that to facilitate adoption, a curriculum must:

- be congruent with strongly held instructor beliefs and values about teaching physics,

- produce improvements in student learning or behavior that are directly observed by the instructor,

- be adoptable with reasonable effort, and

- degrade gracefully, so that less-than-ideal implementations are still reasonably successful.
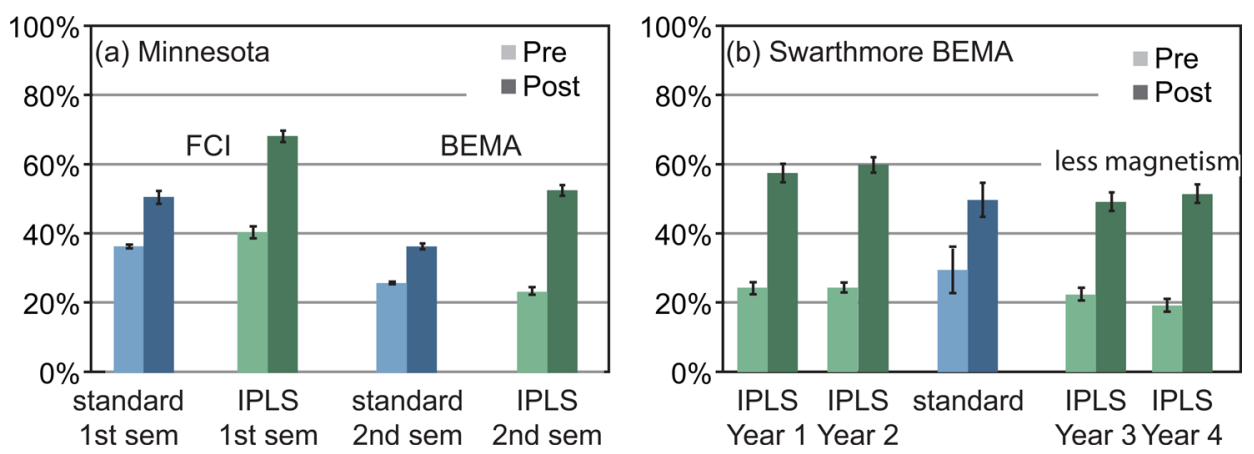

Fig. 4. Pre/post conceptual assessment data from (a) University of Minnesota, both semesters, standard content (pedagogically reformed, $N_{1 \text { st sem }}=1704$, $\left.N_{2 \text { nd sem }}=1263\right)$ and IPLS $\left(N_{1 \text { st sem }}=140, N_{2 \text { nd sem }}=116\right)$ courses; and (b) Swarthmore, second semester standard content $(N=12$, see discussion in text of low numbers) and IPLS course $(N=32,54,63$, and 36 in Years $1-4$, respectively). At Swarthmore, in Years 3 and 4 , significantly less time was spent on magnetism to allow more time on electrostatics in media and circuit models of neural processes. The Force Concept Inventory (FCI) was used in the first semester; the Brief Electricity and Magnetism Survey (BEMA), in the second. Error bars are the standard error of the mean. 
For IPLS courses to become widespread, it will be particularly important to identify where a modified scope and sequence and/or the use of biological contexts violate strongly held physics instructor beliefs or values. This can be accomplished by interviewing faculty who have not taught this course, using artifact-based techniques. ${ }^{49}$ Furthermore, faculty who are willing to test the course materials could be monitored and interviewed to determine the effort (actual and perceived) required to teach the course and their perception of the course's effectiveness at engaging students and fostering student understanding of physics. Finally, it will be essential to provide supporting materials to help instructors understand the goals and design of the course, as well as the biological contexts, well enough to successfully teach it within their time constraints.

\section{CONCLUSIONS}

We have described an approach to teaching physics to life science students in which the scope and sequence of the course have been modified to emphasize the most important physics topics and scientific skills, which are explicitly grounded in life science contexts. Initial results at our two very different institutions suggest that this approach is both practical and promising. Others have also reported success with similar approaches. ${ }^{7-9}$ Our intent in this article is to show that this approach can be successful in diverse contexts and that the specific implementation depends on the specific environment, not to provide a recipe for a "standard" IPLS course.

For those interested in developing or introducing such a course, we note that there is no single best choice of topics, skills, or biological contexts to use, as can be seen in the variations among IPLS courses already in development. Rather, curriculum development teams can use frameworks developed elsewhere and make choices about which specific topics and skills to emphasize, depending on the needs, preparation, and abilities of students and instructors at a specific institution. Instructors adopting the work of such teams are likely to need to make further modifications based on their own outlook, their experiences with students, and the local strengths and constraints of their institution. We expect that future research will provide more specific guidance for effective adaptation strategies, the types of instructional approaches and materials that tend to be most effective, and assessment instruments to help guide the process.

Finally, we note that even if an IPLS course is successful, in order for it to become widespread, most physics faculty at an institution must be willing to teach it. A critical element in accomplishing this is for faculty to judge that they can do so without undue effort. We expect that this will require variety and compromises in the design of the course, as well as a range of suitable instructor support materials.

The IPLS reform effort offers an exciting and timely opportunity for physics and life science educators and education researchers to partner together in work that will have lasting impact. We encourage others to join in this work!

\section{ACKNOWLEDGMENTS}

C.H.C. acknowledges helpful conversations with Suzanne Amador Kane, Timothy McKay, Mark Reeves, Edward F. Redish and the University of Maryland NEXUS team (including providing the course evaluation questions mentioned in Sec. III), Jessica Watkins, and Stamatis Vokos; she also thanks Sanjay Rebello for introducing her to the work of Engle and colleagues. K.H. acknowledges the support of the physics faculty and graduate students at the University of Minnesota and especially conversations with Alexander Grosberg, Pat Heller, and Leon Hsu. This work was supported in part by an Undergraduate Science Education grant from the Howard Hughes Medical Institute to Swarthmore College. Parts of this article have been reprinted with permission from $\mathrm{C}$. H. Crouch and K. Heller, "Teaching Physics to Life Science Students — Examining the Role of Biological Context," PERC 2011 Proceedings, eds. S. Rebello, C. Singh, and P. Engelhardt (Washington DC: American Institute of Physics). (C) 2011 American Institute of Physics.

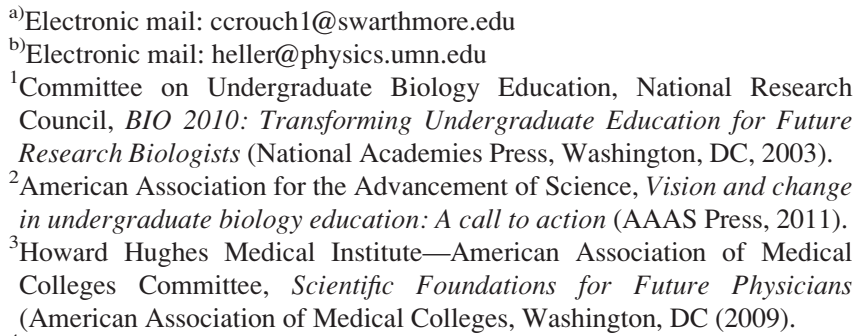

${ }^{4}$ The reasons behind this standard mismatch between the introductory course syllabus and topics of importance to biology are given excellent discussion by E. Brewe, N. J. Pelaez, and T. J. Cooke, "From Vision to Change: Educational initiatives and research at the intersection of physics and biology," special issue of CBE-Life Sciences Education 12, 117-119 (2013). Several of other articles in that issue also discuss this.

${ }^{5}$ J. E. Watkins, K. L. Hall, J. E. Coffey, T. J. Cooke, and E. F. Redish "Disciplinary authenticity: Enriching the reform of introductory physics courses for life science students," Phys. Rev. ST Phys. Ed. Res. 8, 010112 1-17 (2011).

${ }^{6}$ J. Svoboda, V. Sawtelle, B. D. Geller, and C. Turpen, “A framework for analyzing interdisciplinary tasks: implications for student learning and curricular design," Cell Biol. Educ. Life Sci. Educ. 12, p. 187-205 (2013).

${ }^{7}$ See for example the programs for the sessions "Reforming the Introductory Physics Course for Life Science Students" held at the AAPT national meetings since Summer 2009, <www.aapt.org/AbstractSearch>, the CBE-LSE special issue (Ref. 6), and the IPLS Wiki, $<$ www.phys.gwu.edu/iplswiki>, with documents from the NSF-funded 2009 workshop.

${ }^{8}$ D. C. Meredith and E. F. Redish, "Reinventing physics for life-sciences majors," Phys. Today 66(7), 38-43 (2013).

${ }^{9}$ Other articles in this special issue similarly report successful course reforms.

${ }^{10} \mathrm{As}$ an ultimate goal is for students to apply the ideas and skills of physics in learning to another field, such as biology or medicine, it is important to include such applications in the initial learning process. We refer to the ability to apply physics knowledge to solve biological problems as the ability to transfer. However, by "transfer" we mean that students find it easier to learn to use these ideas (physics) in a relatively new context (a different biological problem than one they have previously seen). For example, see D. L. Schwartz, J. D. Bransford, and D. Sears, "Efficiency and innovation in transfer," Transfer of Learning: Research and Perspectives, edited by J. Mestre (Information Age Publishing, Charlotte 2005), pp. 1-51, and Refs. 11-13. This is different than another, more traditional, definition of transfer to mean that something taught in one context can be applied by the student to another context without any further support-for example, that after taking a mathematics course, students in a biology course can use the previously learned mathematics without support. It is controversial whether transfer according to this definition ever occurs among non-experts.

${ }^{11}$ D. K. Detterman "The case for the prosecution: Transfer as an epiphenomenon," Transfer on trial: Intelligence, cognition, and instruction, edited by D. K. Detterman and R. Sternberg (Ablex Publishing, New York, 1993), pp. 1-24. 
${ }^{12}$ D. N. Perkins and T. Grotzer "Teaching intelligence," Am. Psychol. 52, 1125-1133 (1997).

${ }^{13}$ D. F. Halpern "Teaching critical thinking for transfer across domains," Am. Psychol. 53, 449-455 (1998).

${ }^{14}$ A. Collins, J. S. Brown, and A. Holum, "Cognitive apprenticeship: making thinking visible," Am. Educ. 4, 6-46 (Winter 1991).

${ }^{15}$ R. A. Engle, "Framing interactions to foster generative learning: A situative explanation of transfer in a community of learners classroom," J. Learn. Sci. 15(4), 451-498 (2006).

${ }^{16}$ R. A. Engle, P. D. Nguyen, and A. Mendelson, "The influence of framing on transfer: Initial evidence from a tutoring experiment," Instruc. Sci. 39, 603-628 (2011).

${ }^{17}$ For example, G. Benedek and F. Villars, Physics With Illustrative Examples From Medicine and Biology (Addison-Wesley, 1979); R. Bruinsma, "UCLA Physics for Life Science Majors," course notes published by Hayden-McNeil (2006); J. Marion, General Physics with Bioscience Essays (Wiley, New York, 1979); and the Humanized Physics Project, $<$ http://physics.doane.edu/hpp $>$.

18“"To ensure that all students graduate with a basic level of scientific literacy and meet the challenges raised in [the Bio 2010 and SFFP reports] and similar reports, biologists, physicists, chemists, and mathematicians need to look thoughtfully at ways they can introduce interdisciplinary approaches into their gateway courses." Vision and Change (Ref. 2), p. 54.

${ }^{19}$ For example, S. Amador Kane, Introduction to Physics in Modern Medicine (CRC Press, New York, 2002); P. Davidovits, Physics in Biology and Medicine (Academic Press, New York, 2001); R. K. Hobbie, Intermediate Physics for Medicine and Biology (Springer Verlag, New York, 1997), R. K. Hobbie, "Physics useful to a medical student," Am. J. Phys. 42, 121-132 (1975), R. K. Hobbie, "Resource letter MP-1: Medical physics," Am. J. Phys. 53, 822-829 (1985); S. B. Nichparenko, "Premed physics: What and why," J. Coll. Sci. Teach. 14, 391-394 (1985).

${ }^{20}$ See supplementary material at http://dx.doi.org/10.1119/1.4870079. The survey is also available at < groups.physics.umn.edu/physed/Research/ OtherSurveyInstruments/BiologySurvey.pdf/>, and syllabi and materials are available at http://materials.physics.swarthmore.edu/IPLSMaterials; and http://groups.physics.umn.edu/physed/.

${ }^{21}$ Preview Guide for the MCAT 2015 Exam, Second Edition (September 2012), available online at <https://www.aamc.org/students/download/ 266006/data/2015previewguide.pdf/ $>$.

${ }^{22}$ A. Collins, J. S. Brown, and S. E. Newman, "Cognitive Apprenticeship: Teaching the Crafts of Reading, Writing, and Mathematics," in Knowing, learning, and instruction: Essays in honor of Robert Glaser, edited by L. B. Resnick (Lawrence Erlbaum, Hillsdale, NJ, 1990), pp. 453-494.

${ }^{23}$ J. Clement, "Using bridging analogies and anchoring intuitions to deal with students' preconceptions in physics," J. Res. Sci. Teach.30, 1241-1257 (1993).

${ }^{24}$ Based on the approach of G. Novak, E. Patterson, A. Gavrin, and W. Christian, Just-in-Time Teaching: Blending Active Learning and Web Technology (Prentice-Hall, Englewood Cliffs, NJ, 1999) and $<$ http://webphysics.iupui.edu/jitt/jitt.html/>.

${ }^{25}$ D. Hestenes, "Modeling games in the Newtonian world," Am. J. Phys. 60, 732-748 (1992).

${ }^{26}$ C. H. Crouch, J. Watkins, A. P. Fagen, and E. Mazur "Peer Instruction: Engaging students one-on-one, all at once" in Research-Based Reforms in University Physics, edited by E. F. Redish, (American Association of Physics Teachers, College Park, MD, 2007), pp. 1-55. <http://www.compadre.org/PER/items/detail.cfm?ID=4990>

${ }^{27}$ T. O'Kuma, D. Maloney, and C. Hieggelke, Ranking Task Exercises in Physics (Pearson Education, San Francisco, 2000).

${ }^{28} \mathrm{P}$. Heller, R. Keith, and S. Anderson, "Teaching problem solving through cooperative grouping. Part 1: Designing problems and structuring groups," Am. J. Phys. 60, 627-636 (1992).

${ }^{29} \mathrm{P}$. Heller and M. Hollabaugh, "Teaching problem solving through cooperative grouping. Part 2: Group versus individual problem solving," Am. J. Phys. 60, 637-644 (1992).
${ }^{30} \mathrm{P}$. Heller, K. Heller, and T. Foster, "Cooperative group problem solving laboratories for introductory classes," Proceedings of the International Conference on Undergraduate Physics Education (College Park, MD, 1996), College Park: AIP Conference Proceedings Vol. 399, pp. 913-934 (1996).

${ }^{31}$ The details of the following case study are drawn from the course at Swarthmore; the course at Minnesota is very similar.

${ }^{32}$ C. H. Crouch "Capstone examples for second semester IPLS," Presentation at American Association of Physics Teachers Winter 2011 meeting, <http://materials.physics.swarthmore.edu/IPLSTalks/>, (2011).

${ }^{33}$ Based on L. McDermott and P. Shaffer and the University of Washington Physics Education Group, Tutorials in Introductory Physics, 2nd ed. (Pearson, 2013), pp. 185-207.

${ }^{34}$ Instruction draws upon ConcepTests from Mazur, Peer Instruction: A User's Manual, and the University of Washington "Convex Lenses" tutorial (McDermott, Shaffer and the UWPEG, Tutorials in Introductory Physics [Prentice-Hall, Englewood Cliffs, NJ, 2002)] among other sources. The instructional materials are available on the web site.

${ }^{35}$ Panchompoo Wisittanawat, K. Ann Renninger, and Catherine H. Crouch, "The role of interest in physics in the effect of using life science examples in introductory physics," poster presented at Physics Education Research Conference 2013 (Portland, OR, July 2013).

${ }^{36}$ W. K. Adams, K. K. Perkins, N. S. Podolefsky, M. Dubson, N. D. Finkelstein, and C. E. Wieman, "New instrument for measuring student beliefs about physics and learning physics: The Colorado Learning Attitudes about Science Survey," Phys. Rev. ST Phys. Ed. Res. 2, 010101, $1-14$ (2006).

${ }^{37}$ C. H. Crouch, P. Wisttanawat, and K. A. Renninger, "Initial interest, goals, and changes in CLASS scores in introductory physics for life sciences," Proceedings of the Physics Education Research Conference 2013, eds. P. Engelhardt, A. Churukian, and D. Jones (AAPT, Washington, DC, 2013).

${ }^{38}$ Similar MPEX results are reported in G. Kortemeyer, "The Challenge of Teaching Introductory Physics to Premedical Students," Phys. Teach. 45(9), 552-557 (2007).

${ }^{39}$ Statements written by the University of Maryland Physics Education Group and shared as part of collaborations through the NSF project "Creating a Common Thermodynamics" and NEXUS/Physics.

${ }^{40}$ Survey designed and administered by Philip Kudish, Swarthmore College Department of Biology, with Prof. Kathleen Siwicki, as part of the evaluation for the Howard Hughes Medical Institute grant.

${ }^{41}$ D. Hestenes, M. Wells, and G. Swackhammer, "Force concept inventory," Phys. Teach. 30, 141-151 (1992).

${ }^{42}$ L. Ding, R. Chabay, B. Sherwood, and R. J. Beichner, "Evaluating an electricity and magnetism assessment tool: brief electricity and magnetism assessment," Phys. Rev. ST Phys. Ed. Res. 2, 010105-1-7 (2006).

${ }^{43}$ For example, the authors are aware of work underway to develop fluids concept inventories by Vesenka (Univ. of New England) and Meredith (UNH), and by Wagner (Grove City College)

${ }^{44}$ J. Docktor and K. Heller, "Assessment of student problem solving processes," AIP Conf. Proc. 1179, 133-136 (2009).

${ }^{45}$ These are not exhaustive of all the research needed to support IPLS development; for example, work must also be done to characterize the student population on many different lines (i.e. Watkins et al., 2012).

${ }^{46} \mathrm{C}$. Henderson and M. Dancy, "Impact of physics education research on the teaching of introductory quantitative physics in the United States," Phys. Rev. ST Phys. Ed. Res. 5, 020107-1-9 (2009).

${ }^{47}$ E. Yerushalmi, C. Henderson, K. Heller, P. Heller, and V. Kuo, "Physics faculty beliefs and values about the teaching and learning of problem solving. I. Mapping the common core," Phys. Rev. ST Phys. Ed. Res. 3, 020109-1-31 (2007).

${ }^{48}$ E. Yerushalmi, E. Cohen, K. Heller, P. Heller, and C. Henderson, "Instructors' reasons for choosing problem features in a calculus-based introductory physics course," Phys. Rev. ST Phys. Ed. Res. 6, 020108-1-11 (2010).

${ }^{49}$ C. Henderson, E. Yerushalmi, V. H. Kuo, K. Heller, and P. Heller, "Physics faculty beliefs and values about the teaching and learning of problem solving. II. Procedures for measurement and analysis," Phys. Rev. ST Phys. Ed. Res. 3, 020110-1-12 (2007). 